\begin{tabular}{|c|c|c|c|c|c|}
\hline MUNIBE Antropologia-Arkeologia & $n^{\circ} 70$ & $207-218$ & DONOSTIA & 2019 & ISSN 1132-2217 • elSSN 2172-4555 \\
\hline
\end{tabular}

\title{
Los niños de La Cova de Valdavara (Becerreá, Lugo): Análisis morfológico, patológico y del microdesgaste dental
}

\author{
The children from Valdavara Cave (Becerreá, Lugo): \\ A morphological, pathological and dental microwear analyses
}

PALABRAS CLAVES: Subadultos, Edad del Bronce, patologías, CBCT, dieta y agenesia.
GAKO-HITZAK: Azpihelduak, Brontze Aroa, patologiak, CBCT.
KEY WORDS: Subadults, Bronze Age, pathologies, CBCT, diet, agenesis.

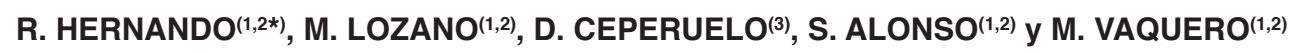

\section{RESUMEN}

Este artículo presenta un análisis holístico de los restos dentales pertenecientes a tres individuos infantiles del yacimiento de la Edad del Bronce de la Cueva de Valdavara (Becerréa, Lugo), mediante diferentes aproximaciones metodológicas, como es el microdesgaste dental, el estudio anatómico externo e interno, y el análisis de patologías. El objetivo de este estudio es obtener una visión más completa de los factores bioculturales (salud oral, dieta, procesamiento del alimento...) que afectaron a la vida de estos individuos. Los resultados muestran una buena salud oral en los tres individuos, siendo destacable la presencia de agenesia dental en el individuo III identificada mediante el análisis con tomografía computarizada de haz cónico (CBCT). Finalmente, los patrones del microdesgaste dental en la superficie bucal revelan una alta abrasividad de los alimentos consumidos, posiblemente por un escaso procesamiento previo de los mismos.

\section{LABURPENA}

Artikulu honek Valdavara leizeko (Becerréa, Lugo) Brontze Aroko aztarnategiko hiru haurren hortz hondakinen azterketa holistikoa dakar. Hurbilketa metodologiko bat baino gehiago erabili ditugu azterketa egiteko; hala nola hortzen mikrohigadura, kanpoko eta barneko azterketa anatomikoa eta patologien analisia. Azterlan honen helburua banako haien bizitzei eragin zien faktore biokulturalen (ahoko osasuna, dieta, elikagaien prozesatzea...) ikuspegi osoagoa eskuratzea da. Emaitzek erakusten dute hiru banakoek ahoko osasun ona zutela eta aipagarria da III. banakoan hortzetako agenesia azaldu izana. Sorta konikoko ordenagailu bidezko tomografiaren (CBCT) bidez identifikatu zen agenesia hori. Azkenik, ahoko hortzen mikrohigaduraren patroiek erakusten du kontsumitzen zituzten elikagaiak oso urratzaileak zirela, agian, aurrez gutxi prozesatzen zituztelako.

\section{ABSTRACT}

This article presents a holistic analysis of the dental remains belonging to three children from the Bronze Age site of Valdavara Cave (Becerréa, Lugo), through different methodological approaches, such as dental microwear, external and internal anatomical study, and the analysis of pathologies. The aim of this study is to obtain a comprehensive perspective of the biocultural factors (oral health, diet, food processing...) that affected the life of these individuals. The results show a good oral health in the three individuals, being remarkable the presence of dental agenesis on the individual III, identified by the analysis with cone beam computed tomography (CBCT). Finally, dental microwear patterns on the buccal surface reveal a high abrasiveness of the diet, possibly due to a scarce processing of the food.

\section{INTRODUCCIÓN}

El estudio en profundidad de individuos infantiles procedentes de contextos arqueológicos es un tema cada vez más recurrente en bioarqueología, debido a que los niños no son sólo un medidor excelente de la salud de una población, sino que pueden aportar infor- mación valiosa sobre diferentes aspectos bioculturales (Halcrow y Tayles, 2008; Cintas-Peña et al. 2018; King et al. 2018). Sin embargo han sido sistemáticamente olvidados o no incluidos en muchos trabajos arqueológicos y antropológicos. Una de las causas principales es la fragilidad de sus restos, lo cual hace que tengan una

\footnotetext{
(1) Àrea de Prehistòria, Universitat Rovira i Virgili (URV), Avinguda de Catalunya 35, 43002 Tarragona, Spain.

(2) IPHES. Institut Català de Paleoecologia Humana i Evolució Social. Zona Educacional 4, Edifici W3, Campus Sescelades 43007. Tarragona, Spain. (3) Department of Restorative Dentistry and Endodontics, Universitat Internacional de Catalunya, C/Josep Trueta s/n, Sant Cugat del Vallès, 08195 Barcelona, Spain.

*Corresponding author (r.hernando90@gmail.com)
} 
menor conservación, además de una representación desigual de los mismos en los yacimientos ya sea por cuestiones culturales o sociales. Todo esto se resume en una infrarrepresentación en los registros arqueológicos (Gibaja et al. 2010), lo que implica que no siempre sea posible realizar análisis en profundidad de los mismos. No obstante, desde hace algún tiempo, los estudios de los individuos infantiles procedentes de contextos arqueológicos están en auge gracias a la integración de las perspectivas biológica y social (Halcrow y Tayles, 2008; Cunha et al. 2015; Cintas-Peña et al. 2018).

En este contexto de creciente interés por el análisis de individuos infantiles es donde enmarcamos nuestro trabajo centrado en el yacimiento de la Cueva de Valdavara (Becerreá, Lugo). En este sistema kárstico se han diferenciado tres localizaciones, Valdavara 1, Valdavara 2 y Valdavara 1-2 (Figura 1). Valdavara 1 es la cavidad principal y contiene una secuencia con niveles de la Prehistoria Reciente y del Paleolítico Superior. Valdavara 2 es otra pequeña cavidad situada $6 \mathrm{~m}$ por debajo de Valdavara 1. Finalmente, se dio la denominación de Valdavara 1-2 a la vertiente intermedia entre ambas cavidades. En Valdavara 2 se ha recuperado un conjunto de restos humanos infantiles, destacando la buena conservación de los mismos, especialmente de su dentición. Por ello, vamos a centrarnos en el análisis de los restos dentales, maxilares y mandibulares de los individuos infantiles recuperados en el nivel 3 de Valdavara 2.

Los restos dentales ofrecen una gran cantidad de información sobre la vida de los individuos ya que se pueden abordar no solo aspectos anatómicos y biológicos como son su desarrollo, crecimiento, y salud en general, sino también aspectos culturales sobre su dieta y estilo de vida a través de análisis más específicos como es el microdesgaste dental (El Zaatari, 2010; Mahoney et al. 2016; Pérez-Pérez et al. 2003; Romero et al. 2013; Schmidt et al. 2015; Schmidt et al. 2019). Además, el hecho de que se conserven mucho mejor que otros elementos esqueléticos ha propiciado el desarrollo de numerosas metodologías para su análisis dando como resultado infinidad de estudios. En este trabajo vamos a aplicar algunas de estas metodologías para caracterizar diversos aspectos de los individuos infantiles de este yacimiento. De este modo, además de la descripción de las características anatómicas de los restos, se procederá a un análisis de los conductos radiculares dentales mediante análisis de imágenes de CBCT y el establecimiento de patrones de microdesgaste dental para determinar la dieta de estos individuos.

Precisamente, la reconstrucción de las dietas de poblaciones del pasado es uno de los temas más tratados en antropología dental a través de diferentes aproximaciones, como, por ejemplo, el estudio de patologías, el macrodesgaste dental, los análisis isotópicos o el microdesgaste dental (Ventresca-Miller et al. 2017; Mays et al. 2017; Scott y Halcrow, 2017). Este último es una herramienta muy útil para caracterizar y diferenciar la dieta de las poblaciones del pasado (Romero et al. 2013; Schmidt et al. 2015; Schmidt et al. 2019), la cual nos permite identificar las propiedades físicas de los alimentos, como son la dureza y la abrasividad, y con ello inferir como fueron procesados los alimentos antes de ser consumidos (Grine, 1986; Lalueza et al. 1996; Pérez-Pérez et al. 2003).

El objetivo de este estudio es, por tanto, inferir las condiciones de vida de estos individuos infantiles, así como otros factores socioculturales a través de diferentes aproximaciones metodológicas (microdesgaste dental, estudio anatómico externo e interno, y análisis de patologías).

\subsection{La Cueva de Valdavara}

El yacimiento de Valdavara está ubicado en el Concello de Becerreá (Lugo), a una altitud de unos 600 m s.n.m, y se compone de tres localizaciones (Valdavara 1, Valdavara 2 y Valdavara 1-2), que forman parte del sistema kárstico que rodea al municipio de Becerreá (Figura 1). Es una zona de rocas arenosas y pizarrosas, con un predominio de las formaciones calcáreas. Los restos humanos objeto de estudio en este trabajo proceden del nivel 3 de Valdavara 2, el cual se caracteriza por una ausencia de elementos de cultura material y un conjunto faunístico relativamente abundante formado por restos de gran bóvido, ciervo común, caprino, carnívoros y lepóridos (Vaquero et al. 2009).

El conjunto de restos humanos tiene una cronología del Bronce Medio, como indican dos dataciones ${ }^{14} \mathrm{C}$ AMS de $3250 \pm 40$ años BP (3.600-3360 años cal. BP) y $3270 \pm 40$ años BP (3.600-3.400 años cal BP), realizadas sobre huesos humanos (Vaquero et al. 2009). El escaso número de restos, su disposición, así como la naturaleza de los mismos ha llevado a concluir que, en ese momento del Bronce Medio, Valdavara 2 podría haber sido un lugar de enterramiento secundario debido a que los elementos recuperados son huesos de mayor tamaño fácilmente reconocibles estando los elementos de tamaño medio y pequeño como los huesos de manos y pies, ausentes (Vaquero et al. 2009). Cabe mencionar que entre el III y el II milenio AC hay una gran variabilidad de tipologías funerarias, no obstante, debido a la escasez de yacimientos de carácter funerario en esta área geográfica y de cronología similar no podemos determinar si el enterramiento infantil en cavidades fue la norma general en esa área (Vaquero et al. 2009). De hecho, el referente más cercano tanto geográfica como cronológicamente (4500 \pm 35 BP) se encuentra en el enterramiento de Pala da Vella (Rubiá, Ourense), en el que se han encontrado escasos restos humanos, pero no de individuos infantiles (Fernández y Villar, 2003).

Los restos humanos encontrados pertenecen a tres individuos infantiles y no hay constancia de restos humanos correspondientes a individuos adultos. No se ha podido determinar si la ausencia de individuos adultos 


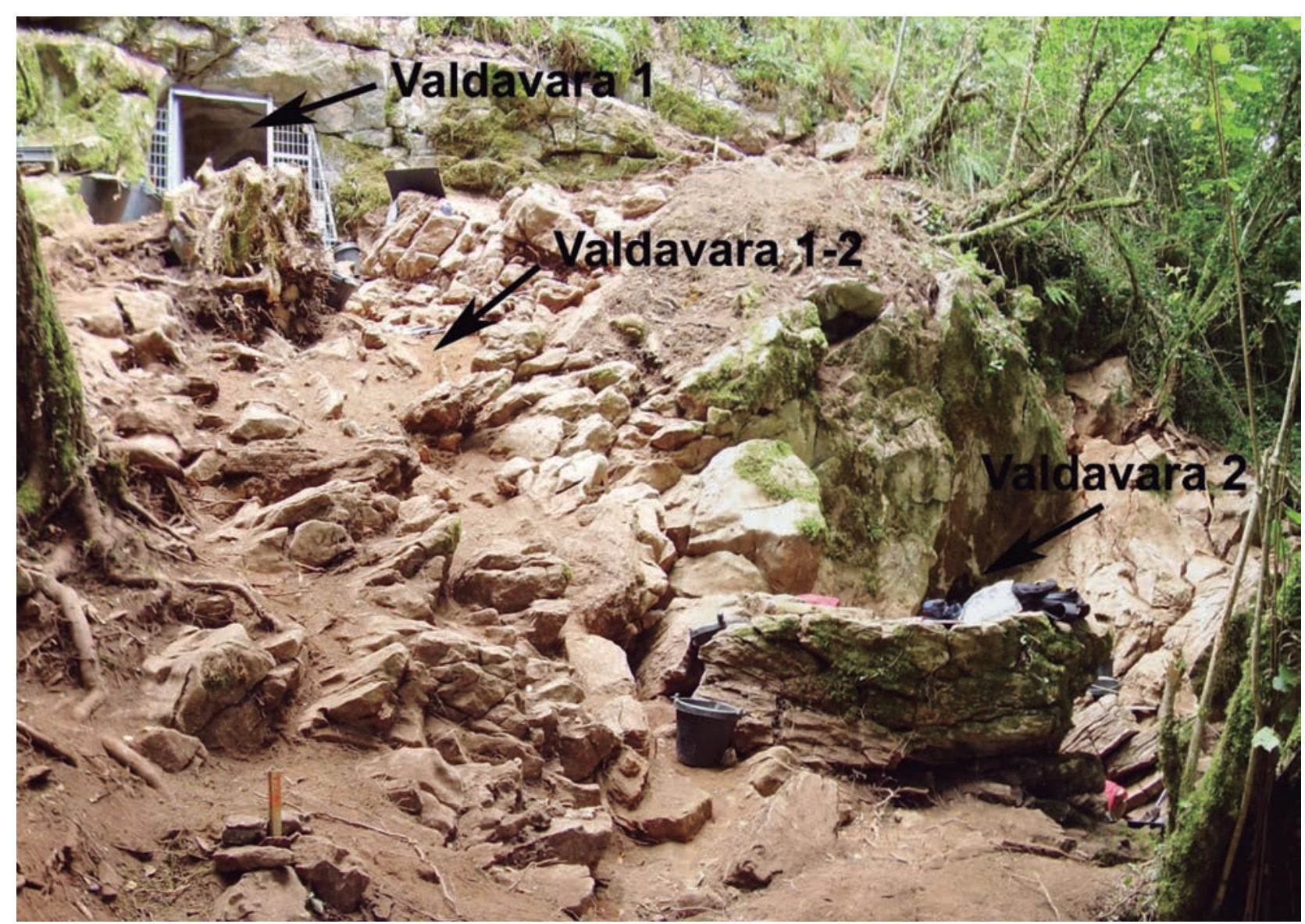

Fig. 1. Fotografía de la Cueva de Valdavara mostrando las tres localizaciones, Valdavara 1, Valdavara 2 y Valdavara 1-2. / Photograph of Valdavara Cave showing the three sites, Valdavara 1, Valdavara 2 y Valdavara 1-2.

está relacionada con el hecho de ser un enterramiento secundario, en el que individuos infantiles y adultos habrían sido tratados de manera distinta.

\section{MATERIAL Y MÉTODOS}

Los restos humanos analizados en este artículo se corresponden con los restos dentales, maxilares y mandibulares recuperados en el nivel 3 de este yacimiento. La totalidad del conjunto recuperado asciende a 55 restos humanos, formado tanto por restos dentales, como craneales y postcraneales.

Las cuestiones relativas al estudio anatómico han tenido en cuenta tanto el elemento anatómico como la determinación de la edad de muerte mediante la valoración de desarrollo dental (formación de corona y raíz), secuencia de erupción y desgaste oclusal.

La identificación anatómica de los restos dentales se ha realizado siguiendo los estándares anatómicos y de terminología establecidos internacionalmente (CarIsen, 1987; Hillson, 1996). Dado que una gran parte de los dientes conservados están en formación, para poder establecer la edad de muerte de los individuos se ha determinado el estado de desarrollo tanto de la corona como de la raíz dental. Además, en el caso de los dientes in situ en mandíbula y maxilar, se ha determinado la secuencia de erupción dental para estimar con mayor precisión la edad de muerte de los individuos (Schour y Massler, 1941; Moorrees et al. 1963; Molnar, 1971; Smith, 1984; Hillson, 1996; AlQahtani et al., 2010).

En concreto, para analizar la anatomía interna de los dientes y el estado de desarrollo de los mismos hemos utilizado imágenes de tomografía computarizada de haz cónico (CBCT) obtenidas con un equipo Planmeca Promax 3D. Este método permite identificar los dientes que no han iniciado el proceso de emergencia y erupción dental, y, por tanto, no son visibles a simple vista. La principal ventaja de esta metodología es el poder realizar exploraciones tridimensionales del esqueleto maxilofacial con una dosis de radiación inferior a otras, como la tomografía computarizada (TC), y con mayor precisión a otros métodos tradicionales como la radiografía. El tiempo de exposición del CBCT se encuentra entre 10 y 40 segundos dependiendo del tipo de escáner y de los parámetros seleccionados principalmente. El tratamiento de las imágenes y los datos registrados se ha llevado a cabo con el software Plan- 
meca Romexis ${ }^{\circledR}$ que las reconstruye y permite visualizarlas en su visión coronal, sagital y axial. Cada proyección de la imagen compone una matriz de pixeles, concretamente $512 \times 512$ pixeles. El conjunto de datos obtenidos del CBCT lo forman unas 580 matrices individuales aproximadamente, que posteriormente son reducidos en datos tridimensionales de 100 millones de vóxels. La composición de la nueva imagen se realiza en pocos minutos (Scarfe y Farman, 2008).

El microdesgaste dental en la superficie bucal, fue analizado a través de un microscopio electrónico de barrido ambiental (MEBA) FEI Quanta 600, que se encuentra en el Servicio de Recursos Científicos y Técnicos de la Universidad Rovira i Virgili (Tarragona), en condiciones de bajo vacío, observando la superficie bucal directamente sobre los originales a 100x, centrándonos en la superficie medial del diente (Galbany et al. 2004). Los parámetros del MEBA se fijaron según la metodología: 20 kV de voltaje y un "spot size" de 4.5 (Galbany et al. 2004). Sólo las imágenes que muestran claramente características de microdesgaste antemortem fueron escogidas para los análisis (Pérez - Pérez et al. 2003). Las imágenes seleccionadas fueron tratadas y cortadas con un área de 0.56 mm2 (Galbany et al. 2004).

Empleando el software libre ImageJ (Schneider, 2012), se hace un recuento del número total de estrías (NT) y de la longitud de las mismas (XT) en micrómetros. Además, se registró la orientación de las estrías en cuatro categorías, de $0^{\circ}$ a $180^{\circ}$ en intervalos de $45^{\circ}$ : verticales $(\mathrm{V})$, horizontales $(\mathrm{H})$, mesiodistales (MD) y distomesiales (DM), (Pérez-Pérez et al. 1994).

\section{RESULTADOS Y DISCUSIÓN}

\subsection{Descripción morfológica y asignación a in- dividuos:}

En el nivel 3 se han recuperado 12 restos dentales, entre dientes aislados y fragmentos mandibulares y maxilares. Análisis previos (Vaquero et al. 2009) concluyeron la presencia de dos individuos en este conjunto, no obstante, el análisis anatómico de la totalidad de los restos al finalizar la excavación del nivel arqueológico unidos con análisis genéticos de las muestras (González-Fortes et al. 2019) han permitido determinar la presencia de tres individuos.

A continuación, se describen los restos, designándolos como Individuo I, Individuo II e Individuo III.

\section{Individuo l:}

El individuo 1, además de los restos dentales, que describiremos pormenorizadamente a continuación, conserva un temporal izquierdo, un fragmento de escápula, 1 fragmento de húmero y 1 de peroné (Vaquero et al. 2009).

- Val2-08-Niv3-S17-R3, este resto se corresponde con un primer incisivo superior derecho perteneciente a la dentición decidua. La corona dental está total- mente formada, pero su estado de mineralización, así como el grado de desarrollo de la raíz, con solamente el tercio cervical formado, indican que este diente es un germen dental en formación y no erupcionado en el momento de la muerte del individuo.

- Val2-08-Niv3-S17-R2, este diente es el antímero del anterior, un primer incisivo superior izquierdo perteneciente a la dentición decidua. Muestra la corona dental totalmente formada y la raíz en un estado de desarrollo ligeramente más avanzado que su antímero. Debido a la mineralización de la corona dental, podemos indicar que estaría empezando a emerger en la cavidad bucal.

- Val2-08-Niv3-S17-R1, es un primer incisivo inferior izquierdo deciduo con la corona totalmente formada y la raíz prácticamente a la mitad de su desarrollo. Es probable que estuviera iniciando su emergencia.

- Val2-08-Niv3-S17-lavado-a, este diente es un segundo incisivo superior derecho deciduo con la corona totalmente formada. Parte de la raíz está rota postdeposicionalmente, pero la zona conservada indica que aún no había alcanzado la mitad de su desarrollo. Este diente aún no habría irrumpido en la cavidad oral.

- Val2-08-Niv3-S17-lavado-b, es un segundo incisivo inferior izquierdo deciduo con la corona totalmente formada y la raíz en estado prácticamente de la mitad de su desarrollo. Es muy probable que estuviera en fase de emergencia.

- Val2-09-Niv3-S17-130, este resto representa un germen dental de un segundo molar inferior izquierdo deciduo. Su estado de formación es inicial ya que solamente está formada la mitad de la corona, habiéndose desarrollado las cinco cúspides y la morfología de la superficie oclusal características de los segundos molares deciduos.

- Val2-08-Niv3-S17-R4, este diente está representado por la corona totalmente formada de un primer molar superior izquierdo de la dentición decidua. La raíz está iniciando su formación.

- Val2-09-Niv3-S17-129, este resto es un fragmento mandibular derecho con los alvéolos de los molares expuestos por mala conservación del hueso alveolar lingual. Pertenece a un individuo infantil con la dentición decidua en formación ya que en uno de los alvéolos conserva el germen de la corona dental de un segundo molar inferior derecho con la corona en tres cuartos de su formación, estando totalmente desarrolladas las cinco cúspides y la morfología oclusal de este tipo de dientes. Todavía no hay indicios de desarrollo de la raíz.

\section{Individuo II:}

El segundo individuo fue identificado a partir del neurocráneo y tiene asociados otros huesos del postcráneo como un fragmento de escápula, 1 fragmen- 
to de húmero, 3 fragmentos de peroné y 1 fragmento de tibia, además de dientes aislados y fragmentos de maxilar con dientes deciduos erupcionados (Vaquero et al. 2009).

- Val2-08-Niv3-S17-145, es un fragmento de maxilar derecho bien conservado con dientes deciduos erupcionados y permanentes en formación. Los dientes deciduos, un canino y el primer molar deciduo, están totalmente erupcionados y formados, incluidos la raíz.

Es destacable el elevado desgaste oclusal que presentan ambos dientes deciduos con gran exposición de dentina. El canino ha perdido más de la mitad de la altura de la corona y en la superficie oclusal solamente conserva un fino reborde de esmalte. En el caso del primer molar, el desgaste oclusal es acusado habiendo perdido las cúspides y aflorando la dentina en la práctica totalidad de esta superficie. En un estadio próximo a la erupción dental se encuentra el primer molar permanente con la corona totalmente formada y desarrollada la mitad de su raíz.

Finalmente, los premolares, tanto Pm3 como Pm4, están in situ en el interior del maxilar con la corona en formación. En el primer premolar se distingue un con- ducto para cada raíz, el vestibular y el lingual (Figura 2). En el segundo premolar no es valorable la conformación de los conductos radiculares ya que no se ha completado la formación de la corona, ni tan solo un tercio de la raíz. En el momento de la muerte del individuo aún estaba presente el diente que lo precede, segundo molar deciduo, y hasta que no avance la formación del segundo premolar el temporal no se exfoliará, y por este motivo no se ha iniciado aún la rizólisis en las raíces del molar deciduo. El primer molar superior se describen dos conductos radiculares en la raíz mesio-vestibular que se unen en el tercio medio, llegando a ser conducto único en apical. En la raíz disto-vestibular y palatina sólo se identifica un conducto por raíz. El segundo molar definitivo insinúa a nivel coronal (en cámara pulpar) un conducto radicular por cada raíz, mesio-vestibular, disto-vestibular y palatina, pero no podemos describirla con exactitud ya que no está completada la conformación de las raíces.

- Val2-09-Niv3-S17-168, es un fragmento de cuerpo maxilar izquierdo (zona del clivus nasoalveolar) que remonta con el resto anterior, indicando que pertenecen al mismo individuo. No conserva ningún diente erupcionado in situ, pero sí dientes permanentes en el interior de los alvéolos. El primer y segundo

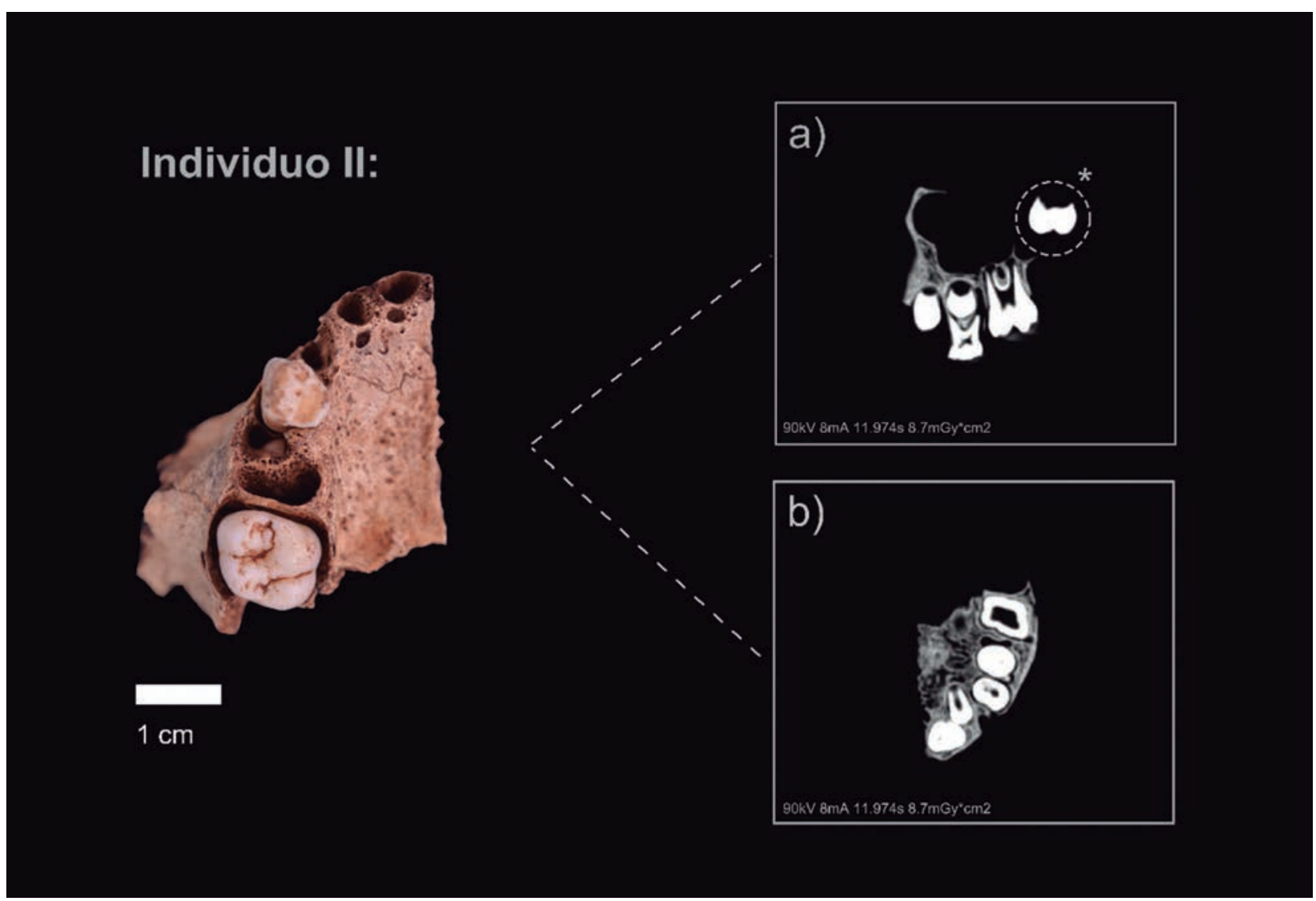

Fig. 2. Cara oclusal del fragmento maxilar derecho perteneciente al individuo II. a) CBCT en posición lateral (antero-posterior). * Es el germen aislado del segundo molar permanente. b) CBCT en posición oclusal del fragmento maxilar. / Occlusal view of the right maxilla from individual II. a) Lateral position on $\mathrm{CBCT}$ in anterior-posterior. * Isolated germen from the second permanent molar. 
incisivo están en fase de formación con la corona totalmente formada, mientras que el canino aún no ha completado su conformación coronal. Sin embargo, ninguno de los tres ha superado la cresta alveolar haciendo acto de presencia en la cavidad oral.

- Val2-09-Niv3-S17-145b, este diente es un germen de un segundo molar superior derecho de la dentición permanente. La corona, con tres cúspides principales, está totalmente formada, y la raíz ha iniciado su desarrollo. Sin embargo, no es valorable el estudio de los conductos radiculares al estar la raíz en una fase inicial de su desarrollo.

\section{Individuo III:}

Este individuo solamente tiene asignado un fragmento de mandíbula con diversos dientes in situ.

- Val2-09-Niv3-S17-146: es el fragmento de mandíbula bien conservada a excepción de las ramas mandibulares perdidas post mortem. El cuerpo mandibular está prácticamente completo en el lado izquierdo llegando a la altura del inicio de la rama mandibular pero no se ha conservado el surco extra-molar. En cambio, en el lado derecho la rotura es anterior a la altura del alveolo del segundo molar. El cuerpo mandibular está completo, aunque hay pérdida postmortem de parte del hueso alveolar en bucal dejando entrever los gérmenes de los dientes anteriores. En la mandíbula, se conservan tanto dientes deciduos erupcionados como dientes permanentes en formación en el interior de los alvéolos. Debido a que los huesos alveolares están rotos pueden apreciarse a simple vista los dientes en formación. Los segundos incisivos y caninos eran dientes funcionales e in situ en el momento de la muerte del individuo. Sin embargo, se han perdido postdeposicionalmente. Los dientes deciduos que se conservan son los primeros molares tanto izquierdo como derecho y el segundo molar derecho. Si analizamos las imágenes obtenidas por CBCT podemos determinar que los incisivos centrales permanentes, tanto el derecho como el izquierdo, se encuentran en período de erupción, puesto que se puede visualizar sus bordes incisales cerca de la cresta alveolar. El incisivo lateral izquierdo muestra dos tercios de la raíz formada y se encuentra en un período de emergencia más adelantado que el incisivo lateral derecho cuya raíz sólo se ha formado un tercio (visible en Figura 3). Los caninos, primeros premolares y segundos molares aún se encuentran en la cripta sin haber iniciado el período de erupción. Los primeros molares están a punto de emerger. En cuanto a los conductos radiculares de incisivos, caninos y primeros premolares se identifica un conducto

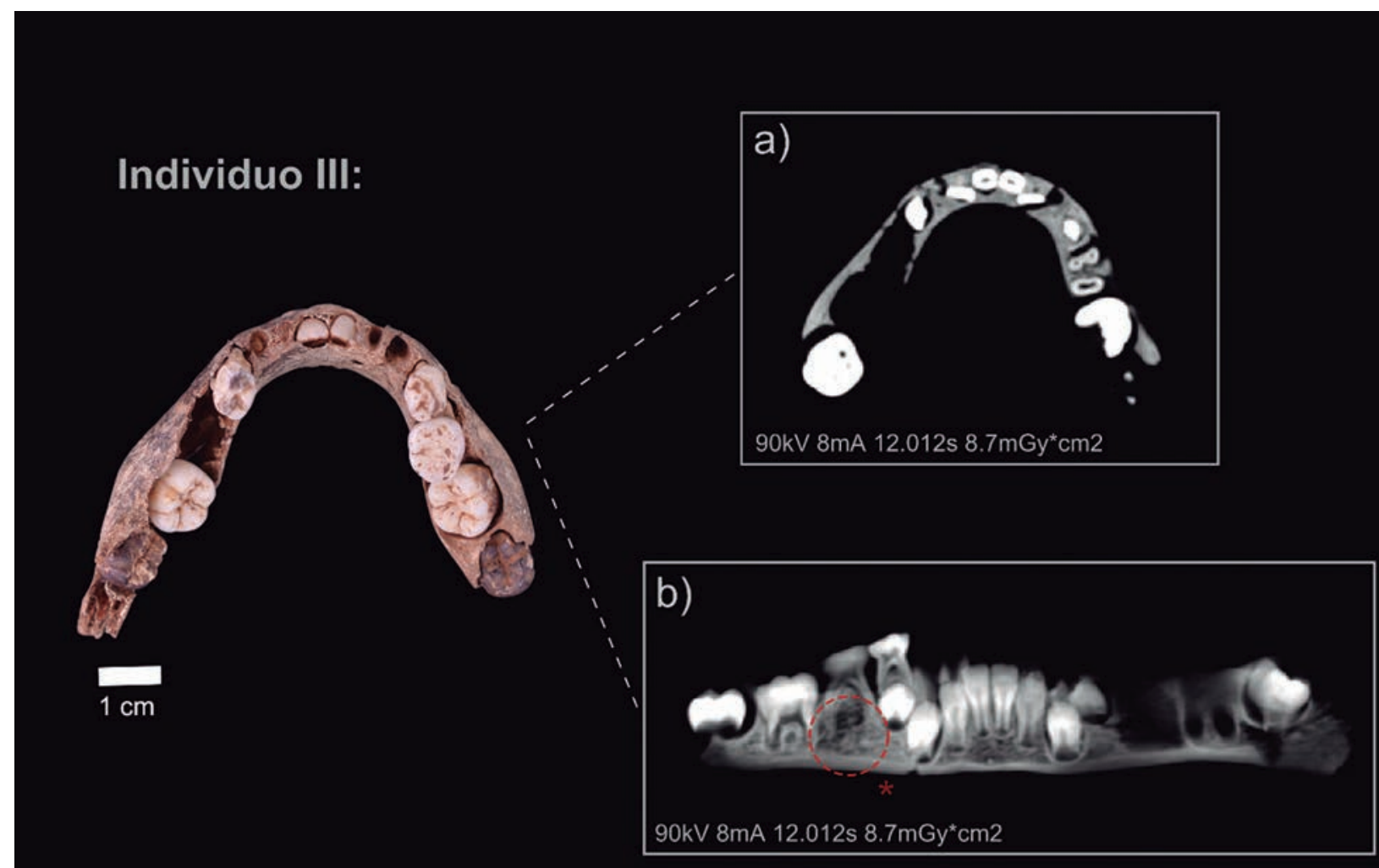

Fig. 3. Cara oclusal de la mandíbula perteneciente al individuo III. a) CBCT de la mandíbula en posición oclusal. b) CBCT de la mandíbula, ortopantomografía. El círculo indica el lugar de la agenesia. / Occlusal view of the mandible from individual III. A) Occlusal position on CBCT of the mandible. B) CBCT of the mandible, orthopantomography. The circle indicates the location of the agenesia. 
único centralizado. El primer molar temporal en su raíz mesial posee dos conductos (uno vestibular y otro lingual) mientras que la raíz distal muestra un solo conducto (Figura 3). Los primeros molares definitivos describen dos conductos radiculares tanto en la raíz mesial como en la distal, uno vestibular y otro lingual. No es valorable la conformación interna radicular del segundo molar inferior derecho al no tener iniciada la formación de la raíz.

Los molares deciduos, tanto los primeros molares como el segundo molar, presentan desgaste del esmalte dental en la superficie oclusal y presencia de exposición de dentina más acusada en las cúspides bucales, además de indicios de reabsorción radicular.

\subsection{Patologías}

Los restos dentales de estos tres individuos se han analizado en busca de patologías no habiéndose encontrado ninguna evidencia de patología bucodental como caries o hipoplasia de esmalte. Sin embargo, en el individuo III se ha determinado la ausencia o agenesia de los segundos premolares de forma bilateral, que es clara en el lado derecho y se insinúa su ausencia en el lado izquierdo. En este tercer cuadrante o lado izquierdo se ha exfoliado el primer molar deciduo, pero podemos calcular la distancia de distal del primer premolar a mesial del primer molar y al obtener la misma distancia que en el lado izquierdo, podemos confirmar agenesia bilateral con exactitud.

\subsection{Microdesgaste dental}

Los resultados obtenidos del microdesgaste dental se muestran en la Tabla 1. No ha sido posible realizar un análisis estadístico debido a que la muestra es de tan solo dos individuos.

Sin embargo, dado el número tan alto de estrías se decidió compararlos con otros grupos del mismo rango de edad (0-6 años) y cronologías similares de la Península Ibérica. Los yacimientos seleccionados fueron: Cova de la Guineu, Font-Rubí, Barcelona; El Portalón, Sierra de Atapuerca, Burgos; El Alto de la Huesera, Laguardia, Álava; Galls Carboners, Mont-Ral, Tarragona; y La Olmeda, Palencia (García-Gonzalez et al. 2018; Pérez-Pérez et al. 1994), (Figura 4, Tabla 2).

\section{DISCUSIÓN}

El nivel 3 de Valdavara 2 ha proporcionado restos dentales, mandibulares y maxilares correspondientes a un número mínimo de tres individuos. El Individuo I tendría una edad de muerte estimada en base a la secuencia de desarrollo y erupción dentales, de entre seis y nueve meses. Esta edad de muerte estimada se ve corroborada por el análisis de otros elementos esqueléticos y craneales asociados al mismo individuo como son el estado de desarrollo del hueso timpánico, donde el tubérculo posterior no está fusionado al anterior (Vaquero et al. 2009). Por otra parte, para el Individuo II, teniendo en cuenta el estado de desarrollo dental y el grado de desgaste oclusal de los dientes deciduos, se estima una edad de muerte cercana a los cinco-seis años, mientras que para el Individuo III, en base a los mismos criterios, se ha establecido una edad de muerte de entre 4-5 años.

Relativo a las patologías, el estado de salud oral de estos individuos es bueno ya que no se han identificado patologías dentales relacionadas ni con la alimentación ni con la falta de higiene dental como caries o cálculo ni marcadores de estrés metabólico como hipoplasias. No obstante, es destacable la agenesia bilateral de los segundos premolares inferiores identificada en el individuo III. Agenesia dental es el término que se refiere a la ausencia congénita del desarrollo de una o más piezas dentales y puede afectar tanto a la dentición primaria (con menor frecuencia) como a la permanente (Hillson, 1996; Pemberton et al. 2005; Zegan et al. 2012). Se diferencian básicamente tres tipos de agenesias: la agenesia múltiple u oligodoncia, la agenesia total o anodoncia y la agenesia aislada o hipodoncia, que

\begin{tabular}{|c|c|}
\hline VARIABLES & TOTAL \\
\hline TN & $136.5(13.43)$ \\
\hline $\mathbf{X T}$ & $125.8(2.36)$ \\
\hline NV/TN & $0.37(0.13)$ \\
\hline NH/TN & $0.10(0.11)$ \\
\hline
\end{tabular}

Tabla 1: Estadística descriptiva de la superficie bucal de los individuos de Valdavara. Los valores se componen de media de las variables y su desviación estándar entre paréntesis. Variables: TN (número de estrías); XT (longitud de las estrías); NV/TN (número de estrías verticales dividido por el total de estrías) y NH/TN (número de estrías horizontales dividido por el total de estrías)

\begin{tabular}{|l|c|c|c|c|}
\hline \multicolumn{1}{|c|}{ YACIMIENTO } & LOCALIZACIÓN & CRONOLOGÍA & RANGO DE EDAD & NT \\
\hline COVA DE LA GUINEU & Font-rubí, Barcelona & Neolítico Final & $2-4$ años & 48.8 \\
\hline GALLS CARBONERS & Mont-Ral, Tarragona & Edad del Bronce & $3-4$ años & 73.7 \\
\hline LA OLMEDA & Palencia & Medieval & $2-5$ años & 56.6 \\
\hline EL PORTALÓN & Sierra de Atapuerca, Burgos & Calcolítico & $5-7$ años & 107 \\
\hline EL ALTO DE LA HUESERA & Laguardia, Álava & Calcolítico Final & $5-6$ años & 108 \\
\hline VALDAVARA & Becerreá, Lugo & Edad del Bronce & $4-6$ años & 136.5 \\
\hline
\end{tabular}

Tabla 2: Localización de los yacimientos con su cronología correspondiente. Rango de edad de los individuos infantiles y el número de estrías totales en la superficie bucal (NT). 
es la más frecuente, siendo el caso que nos ocupa. En poblaciones actuales, la prevalencia de esta condición en la dentición permanente es de entre 2,3 a 11,3\%, siendo los individuos femeninos los más afectados (Zegan et al. 2012). Si nos centramos exclusivamente en la falta de segundos premolares, la incidencia es de un 3,1\% (Polder et al. 2004). En dentición permanente los segundos premolares suelen representar el 40-50\% de los casos de agenesia, excluyendo de estos datos los terceros molares que son los más frecuentemente afectados por esta condición. Los caninos y los primeros molares son los dientes filogenéticamente más estables y, por lo tanto, son los menos afectados por la hipodoncia (García-Barbero, 2005). La ausencia unilateral de segundos premolares suele ser más frecuente respecto a la bilateral, ya que se da en un 54,5\% de los casos (Polder et al. 2004). Los incisivos también se encuentran entre los dientes que presentan una mayor agenesia. En todas las categorías dentales, los dientes superiores son los más afectados. Los dientes distales (segundos premolares, segundos incisivos y terceros molares) son los más propensos a esta ausencia congénita debido a que en su formación están más influenciados por factores medioambientales y, también suelen ser los que presentan una mayor variabilidad en su morfología (Zegan et al. 2012).

La etiología de la agenesia dental es compleja ya que la formación dental tiene un origen multigénico y, por tanto, es complicado establecer una única causa (Polder et al. 2004). No obstante, entre las causas más comúnmente propuestas se encuentran la obstrucción o disrupción de la lámina dental, anormalidades en el epitelio dental, fallo del desarrollo en la mesénquima y, en general, espacio limitado en la mandíbula o maxilar (Zegan et al. 2012). Obedece sobre todo a factores genéticos y puede responder a distintos patrones de herencia, más frecuente de tipo autosómica dominante, o bien poligénica. Como causas generales, por tanto, la agenesia dental está relacionada con un fuerte componente hereditario ya que diversos miembros de una misma familia pueden presentar agenesias y también puede estar acompañada de algunos síndromes como diferentes tipos de displasia o síndrome de Down. Entre causas más locales, las fracturas o traumatismos en mandíbula y maxilar, así como extracciones tempranas de dientes primarios, e incluso, enfermedades graves y malnutrición se han relacionado con la falta de desarrollo dental. Además, en la literatura médica se destaca la presencia de otros síntomas orales asociados a la agenesia dental como micro o macrodontia, retraso en el desarrollo general de la dentición, retención de dientes primarios, hipocalcificación, dentinogénesis imperfecta, e incluso malformaciones óseas mandibulares y maxilares (Zegan et al. 2012).

En el individuo infantil de Valdavara no hemos detectado ninguna otra anomalía oral, ni evidencias de traumatismos o de estrés nutricional. Por tanto, no podemos establecer una causa concreta para esta hipo- dontia más allá de relacionarlo con la tendencia evolutiva de mandíbulas y maxilares de tamaño cada vez más reducido que dificulta la correcta formación, erupción y alineación dental. En general, la ausencia de uno o más dientes, puede conllevar problemas de malposicionamiento dental y de oclusión que afecten a la vida del individuo. En este caso, no podemos establecer este particular ya que el individuo afectado murió antes de la edad de erupción gingival de estos dientes.

En la literatura antropológica hemos encontrado diversos casos de hipodontia, siendo los más antiguos la agénesis de los segundos premolares mandibulares del individuo infantil (ca. 9 años) Qafzeh 15 datado en 92.000 años B.P., así como la ausencia de un incisivo mandibular en el individuo infantil neandertal de Devil's Tower de Gibraltar y en el individuo juvenil, también neandertal, de Malarnaud (Tillier et al. 1998; Trinkaus, 2018). Posteriormente, y como referente más cercano a nuestro caso de estudio, encontramos la agénesis bilateral de incisivos de un individuo adulto de la Edad del Bronce del yacimiento siberiano de Ust'-Ida I (Lieverse et al. 2014).

Dejando a un lado las cuestiones relacionadas con la agenesia dental, el análisis del patrón de microdesgaste dental nos ha permitido conocer algunos aspectos de la dieta de estos individuos. Es importante destacar que los datos pertenecen a dos individuos (Individuo II y III) y deben tratarse exclusivamente a nivel individual, sin poder extrapolarlos a nivel de población ya que carecemos de información de la población adulta. Para inferir la dieta a partir de la faceta bucal de los dos individuos de Valdavara analizados hay que tener en cuenta una serie de variables. Una de ellas es el número total de estrías (NT) que indica la abrasividad de la comida (Teaford y Lytle, 1996). Alimentos abrasivos como cereales (por su contenido de fitolitos) o la inclusión de partículas extrínsecas debido al procesamiento previo de la comida provocan un mayor número de estrías (NT), (Ryan, 1979; Gordon, 1988; Pérez-Pérez et al. 1994). Si tenemos en cuenta esta variable en los individuos de Valdavara en comparación con otras poblaciones infantiles similares, llama la atención el número mayor de estrías en los individuos de Valdavara en comparación con otros grupos del mismo rango de edad y cronología similar (Tabla 2; Figura 4).

Estas diferencias significativas respecto al resto son interesantes ya que estos dos individuos tienen una edad cercana al período de introducción y consolidación tanto de comidas complementarias como papillas o semilíquidos (Sellen y Smay, 2001; Halcrow y Tayles, 2008; Meehan et al. 2013; Mays, 2016; Mays et al. 2017; Ventresca-Miller et al. 2017; Scott y Halcrow, 2017), como de alimentos más propios de la dieta adulta.

El escaso procesamiento de estos alimentos puede afectar de modo significativo al microdesgaste, es decir, el molido previo de los cereales puede dejar una serie de partículas minerales mezcladas en el alimen- 


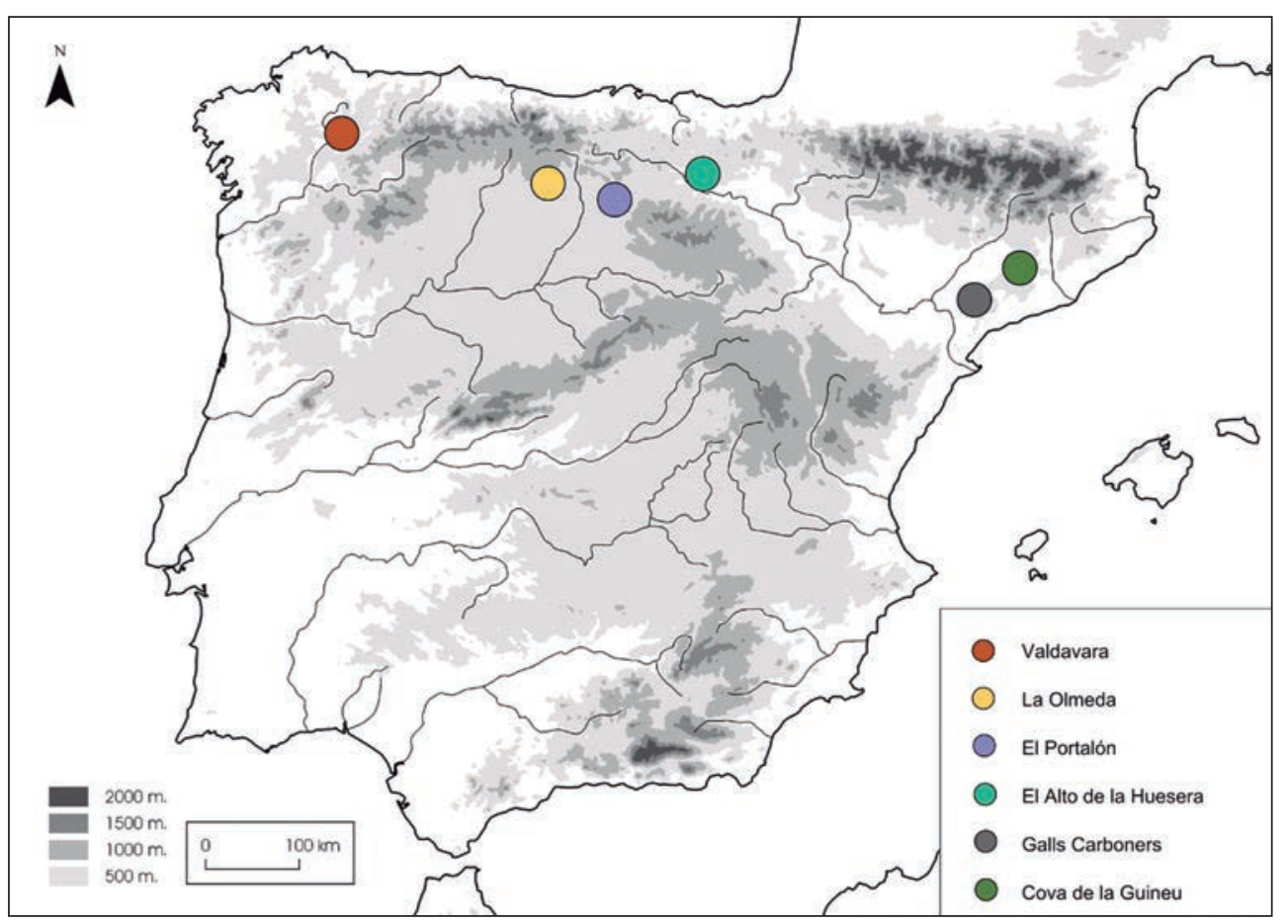

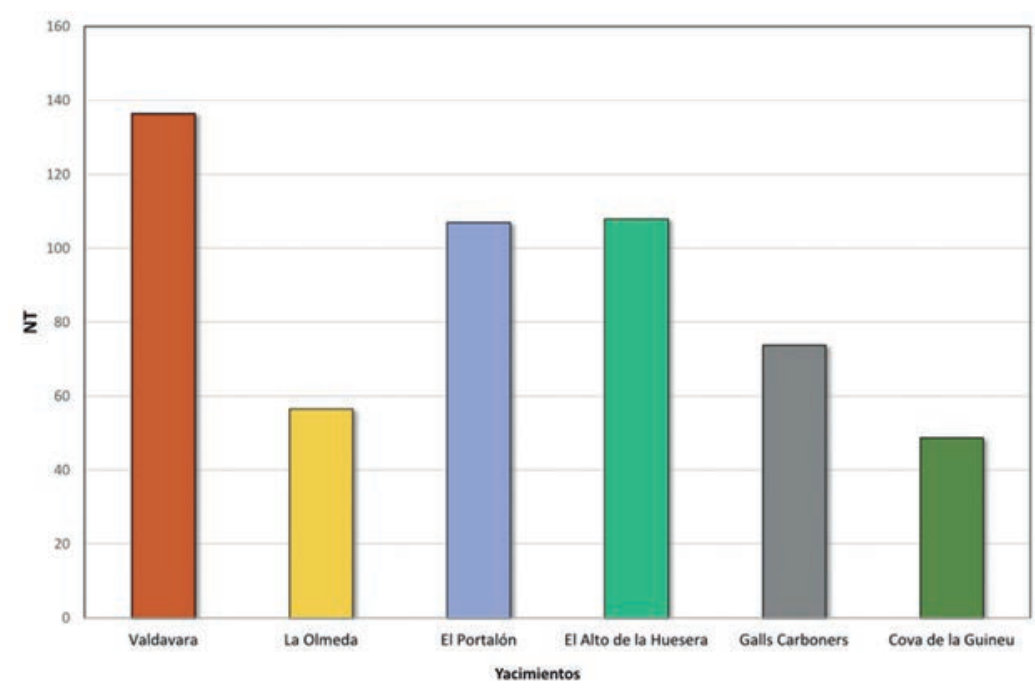

Fig. 4. En la parte posterior de la figura se muestra la localización geográfica de los yacimientos con restos dentales infantiles en la Península Ibérica. Mientras que en la parte inferior, se representa en un gráfico de barras e número de estrías totales (NT) en la superficie bucal pertenecientes a cada individuo. / On top, geographic location of the archaeological sites with child dental remains in the Iberian Peninsula. On the bottom, bar chart with the total number of striations (TN) on the buccal surface. to e incrementar su abrasividad (Teaford et al. 1996; Gügel et al. 2001; Mahoney et al. 2016; Mays, 2016; Ventresca-Miller et al. 2017; Scott y Halcrow, 2017). La inclusión de estas partículas extrínsecas a través del molido con un molino de piedra causa una mayor microestriación en el esmalte, ya que la dureza de estas partículas es mayor que la del esmalte (Pérez-Pérez et al. 1994; Gügel et al. 2001; Polo-Cerda et al. 2007; Romero y De Juan, 2007; Galbany et al. 2008; Jarosová, 2008; Schmidt et al. 2015 Soltysiak, 2011). Aunque no se han encontrado evidencias de molinos en Valdavara (Vaquero et al. 2009), sabemos que las poblaciones del Bronce final del Noroeste ibérico poseían molinos cuya función está relacionada con el machado del ce- real para la obtención de la harina (Teira y Rodríguez, 2014). Por todo ello, el escaso procesamiento previo de los alimentos es una de las hipótesis que explicaría el alto nivel de abrasividad en la dieta de estos dos individuos de Valdavara.

Sin embargo y sin ser excluyente, este elevado número de estrías (NT), también puede ser debido a una dieta similar a la adulta, aunque la ausencia de individuos adultos en Valdavara 2 impide una comparación entre ambos grupos de edad. Esta dieta se basaría en la inclusión de alimentos más duros o que requieren más tiempo de masticación y en consecuencia, producen un patrón de microdesgaste caracterizado por un mayor número de estrías. Llegados a este punto hay 
que tener presente otra variable, la longitud de las estrías (XT), la cual depende no sólo de la dureza de los alimentos sino también de la presión ejercida por los músculos al masticar (Pérez-Pérez et al. 1994). Ambas variables tienen valores similares a los de una población adulta del yacimiento de Aspe, Alicante, con la misma cronología que Valdavara $(\mathrm{TN}=135.00 ; \mathrm{XT}=126.83 \mu \mathrm{m})$, (Romero et al. 2004). No obstante, no es infrecuente hallar ejemplos de individuos infantiles de edades similares a los analizados aquí, donde se documenta un elevado grado de macrodesgaste dental, que debemos indicar que también se ha documentado en los Individuos II y III de Valdavara. Este elevado macrodesgaste dental se asocia a una dieta dura y abrasiva, como es el caso de un individuo de unos cinco años de edad de muerte del yacimiento calcolítico de La Cima (Sevilla) (Alcázar Godoy et al. 1992). Igualmente, estudios etnográficos de poblaciones preindustrales, corroboran la inclusión de comidas sólidas a una edad temprana (Sellen y Smay, 2001). Además, un estudio isotópico sobre niños del Alto de la Huesera (Neolítico Final, Rioja Alavesa), con el mismo rango de edad que los individuos de Valdavara, afirma que tienen valores isotópicos similares a adultos, sugiriendo que estos niños tendrían una dieta similar a la que consumieron los adultos (Fernández-Crespo et al. 2018).

Los resultados aportados por los diferentes estudios realizados indican que estos tres niños no sufrieron enfermedades asociadas a estrés metabólico durante su vida ya que no han quedado reflejadas en el patrón de crecimiento dental. Asimismo, tampoco podemos establecer una causa de la muerte ya que no hay evidencias en sus huesos y dientes que permitan establecer hipótesis al respecto. No obstante, la edad de muerte de los tres individuos recuperados en Valdavara está situada entre los 0 y los seis años de edad, situándolos en los grupos de edad correspondientes con lactantes y primera infancia siendo los individuos más frágiles de las poblaciones humanas.

\section{CONCLUSIONES}

A través de las diferentes técnicas usadas en este estudio podemos inferir factores bioculturales, como la dieta, salud oral, o el procesamiento de la comida entre otros, que afectan a estos individuos infantiles de Valdavara aportando una visión más completa sobre su estilo de vida.

A nivel biológico, los escáneres CBCT y el análisis de las patologías, nos muestran un nuevo caso de agenesia dental en el individuo III. Aunque no se puede concluir una causa concreta a esta patología, como estés nutricional o traumatismo, es un dato relevante que añade un caso más de esta anomalía oral al registro fósil.

Dentro de la dieta mixta que caracterizaría a las poblaciones de la Edad del Bronce, el análisis del microdesgaste dental de los individuos de Valdavara, nos permite inferir una dieta más abrasiva para estos niños siendo más similar a una dieta "adulta", que se caracteriza por un escaso procesamiento previo de la comida en comparación con otras poblaciones de edades similares.

\section{AGRADECIMIENTOS}

Los autores quieren agradecer a los revisores anónimos que ayudaron a mejorar este artículo. Las excavaciones fueron financiadas por el Concello de Becerreá. R.H tiene una beca predoctoral Martí i Franquès (2019PMF-PIPF-59). Proyectos: MICINN-FEDER PGC2018-093925-B-C32; AGAUR (Ref. 2018SGR1040); HAR2016-76760-C3-1-P.

\section{BIBLIOGRAFÍA}

Alcázar Godoy, J., Martín Espinosa, A., Ruiz Moreno, M.T., 1992. Enterramientos calcolíticos en zonas de hábitat. Revista de Arqueología año XII 137, 18-27.

AIQahtani, S. J., Hector, M.P., Liversidge, H.M., 2010. Brief communication: the London atlas of human tooth development and eruption. American Journal of Physical Anthropology 142(3), 481-490.

Carlsen, O., 1987. Dental morphology. Munksgaard.

Cintas Peña, M., García Sanjuán, L., Díaz-Zorita Bonilla, M., Herrero Corral, A.M., Robles Carrasco, S., 2018. The non-adult population at the Copper Age settlement of Valencina de la Concepción (Seville, Spain): a demographic, contextual and sociological approach. Trabajos de Prehistoria, 75(1), 85-108.

Cunha, C., Silva, A.M., Pereira, D., Tomé, T., Paredes, J., Cabrita, C. 2015. Children of the grave: contribution of non-adult individuals in some human osteological series from collective burials in the Late Prehistory of the Iberian Peninsula. In: Death as Archaelogy of Transition: Thoughts and Materials. Papers from the II International Conference of Transition Archaeology: Death Archaeology (Evora, Portugal 2013), 177-188. British Archaeological Reports, International Series.

El-Zaatari, S., 2010. Occlusal microwear texture analysis and the diets of historical/prehistoric hunter-gatherers. International Journal of Osteoarchaeology 20, 67-87. https://doi. org/10.1002/oa.1027

Fernández-Crespo, T., Czermak, A., Lee-Thorp, J.A., Schulting, R.J., 2018. Infant and childhood diet at the passage tomb of Alto de la Huesera (north-central Iberia) from bone collagen and sequential dentine isotope composition. International Journal of Osteoarchaeology 28, 542-551.

Fernández Rodríguez, C., Villar Quinteiro, R., 2003. Prospección y excavación de cuevas en la cuenca del Sil (Rubiá, Ourense): La Pala da Vella. Brigantium 14, 13-22.

Galbany, J., Martínez, L.M., Pérez-Pérez, A., 2004. Tooth replication techniques, SEM imaging and microwear analysis in primates: methodological obstacles. Anthropologie 42(1), 5-12.

Galbany, J., Garriga, N., Majoral-Salichs, M., Coll Monteagudo, R., Fluxà, J., 2008. Microdesgaste y patología dental en la población de la Edad de Bronce de "Mar i Muntanya" (Alella, Barcelona). Revista Española de Antropología Física.

García Barbero, J., 2005. Patología y terapéutica dental. Síntesis, Madrid. 
García-González, R., Sánchez-Puente, Z., Arsuaga, J.L., Carretero, J.M., 2018. Dietary inferences from dental microwear patterns in Chalcolithic populations from the Iberian Peninsula: the case of El Portalón de Cueva Mayor (Sierra de Atapuerca, Burgos, Spain) and El Alto de la Huesera (Álava, Spain). Archaeological and Anthropological Sciences 1-13.

Gibaja, J.F., Majó, T., Chambon, P., Ruiz Ventura, J., Subirà, M. 2010. Prácticas funerarias durante el Neolítico. Los enterramientos infantiles en el noreste de la Península Ibérica. Complutum 21(2), 47-68.

González-Fortes G., Tassi F., Trucchi E., Henneberger K., Paijmans J.L.A., Díez-del-Molino D., Schroeder H., Susca R., Barroso-Ruíz C., Bermudez F. J., Barroso-Medina C., Bettencourt A.M.S., Sampaio H.A., Grandal-d'Anglade A., Salas A., de Lombera, H.M., Fabregas, R., Vaquero, M., Alonso, S., Lozano, M., Rodríguez-Alvarez, X.P., Fernández-Rodríguez, C., Manica, A., Hofreiter, M., Barbujani, G., 2019. A western route of prehistoric human migration from Africa into the Iberian Peninsula. Proceedings of the Royal Society B: Biological Sciences 286, 20182288. https://doi.org/10.1098/rspb.2018.2288.

Gordon, K.D., 1988. A review of methodology and quantification in dental microwear analysis. Scanning microscopy 2 , 1139-1147.

Grine, F.E., 1986. Dental evidence for dietary differences in Australopithecus and Paranthropus: a quantitative analysis of permanent molar microwear. Journal of Human Evolution 15, 783-822.

Gügel, I.L., Grupe, G., Kunzelmann, K., 2001. Simulation of dental microwear: characteristic traces by opal phytoliths give clues to ancient human dietary behavior. American Journal of Physical Anthropology: The Official Publication of the American Association of Physical Anthropologists 114, 124-138.

Halcrow, S.E., Tayles, N., 2008. The Bioarchaeological Investigation of Childhood and Social Age : Problems and Prospects. Journal of Archaeological Method and Theory 15(2), 190-215. https://doi.org/10.1007/s10816-008-9052-x.

Hillson, S., 1996. Dental anthropology. Cambridge University Press.

Jarosová, I., 2008. Dietary inferences using buccal microwear analysis on the LBK population from Vedrovice, Czech Republic. Anthropologie 46(2), 175-184.

King, C.L., Snoddy, A.M., Millard, A.R., Gröcke, D.R., Standen, V.G., Arriaza, B.T., Halcrow, S.E., 2018. A multifaceted approach towards interpreting early life experience and infant feeding practices in the ancient Atacama Desert, Northern Chile. International Journal of Osteoarchaeology 28, 599-612.

Lalueza, C., Perez-Perez, A., Turbon, D., 1996. Dietary Inferences Through Buccal Microwear Analysis of Middle and Upper Pleistocene Human Fossils. American Journal of Physical Anthropology 100, 367-387.

Lieverse, A.R., Temple, D.H., Bazaliiskii, V.I., 2014. Paleopathological description and diagnosis of metastatic carcinoma in an Early Bronze Age (4588+ $34 \mathrm{Cal}$. BP) forager from the Cis-Baikal region of Eastern Siberia. PloS one 9, e113919.

Mahoney, P., Schmidt, C.W., Deter, C., Remy, A., Slavin, P., Johns, S.E., Miszkiewicz, J.J., Nystrom, P., 2016. Deciduous enamel 3D microwear texture analysis as an indicator of childhood diet in medieval Canterbury, England. Journal of Archaeological Science 66, 128-136.
Mays, S., 2016. A study of the potential of deciduous incisor wear as an indicator of weaning using a human skeletal population. International Journal of Osteoarchaeology 26, 725-731.

Mays S., Gowland R., Halcrow S., Murphy E., 2017. Child Bioarchaeology: Perspectives on the Past 10 Years. Childhood in the Past 1-19.

Meehan, C.L., Roulette, J.W., 2013. Early supplementary feeding among central African foragers and farmers: a biocultural approach. Social science \& medicine 96, 112-120

Molnar, S., 1971. Human tooth wear, tooth function and cultural variability. American Journal of Physical Anthropology 34, 175-189.

Moorrees, C.F.A., Fanning, E.A., Hunt, E.E., 1963. Age variation of formation stages for ten permanent teeth. Journal of dental research 42, 1490-1502.

Pemberton, T. J., Das, P., Patel, P. I., 2005. Hypodontia:genetics and future perspectives. Brazilian Journal Oral Science 4(13), 695-706.

Pérez-Pérez, A., Lalueza, C., Turbón, D., 1994. Intraindividual and intragroup variability of buccal tooth striation pattern. American Journal of Physical Anthropology 94, 175-187.

Pérez-Pérez, A., Espurz, V., de Castro, J.M.B., de Lumley, M.A., Turbón, D., 2003. Non-occlusal dental microwear variability in a sample of Middle and Late Pleistocene human populations from Europe and the Near East. Journal of Human Evolution 44, 497-513

Polder, B.J., Van't Hof, M.A., Van der Linden, F.P.G.M., Kuijpers-Jagtman, A.M., 2004. A meta-analysis of the prevalence of dental agenesis of permanent teeth. Community dentistry and oral epidemiology 32, 217-226.

Polo-Cerdá, M., Romero, A., Casabó, J., De Juan, J., 2007. The Bronze Age burials from Cova Dels Blaus (Vall d'Uixó, Castelló, Spain): An approach to palaeodietary reconstruction through dental pathology, occlusal wear and buccal microwear patterns. HOMO,Journal of Comparative Human Biology 58, 297307. https://doi.org/https://doi.org/10.1016/j.jchb.2006.10.005

Romero, A., Martínez-Ruiz, N., De Juan, J., 2004. Non-occlusal dental microwear in a Bronze-Age human sample from east Spain. Anthropologie 42, 65-70.

Romero, A., De Juan, J., 2007. Intra-and interpopulation human buccal tooth surface microwear analysis: inferences about diet and formation processes. Anthropologie 45, 61-70.

Romero, A., Ramírez-Rozzi, F.V., De Juan, J., Pérez-Pérez, A., 2013. Diet-Related Buccal Dental Microwear Patterns in Central African Pygmy Foragers and Bantu-Speaking Farmer and Pastoralist Populations. PLOS ONE 8, e84804.

Ryan, A.S., 1979. Wear striation direction on primate teeth: A scanning electron microscope examination. American Journal of Physical Anthropology 50, 155-167. https://doi.org/10.1002/ ajpa.1330500204

Scarfe, W.C., Farman, A.G., 2008. What is cone-beam CT and how does it work? Dental Clinics of North America 52, 707-730.

Schmidt C.W., Beach J.J., McKinley J.I., Eng J.T., 2015. Distinguishing dietary indicators of pastoralists and agriculturists via dental microwear texture analysis. Surface Topography: Metrology and Properties 4:14008.

Schmidt, C. W., Remy, A., Van Sessen, R., Willman, J., Krueger, K., Scott, R., Chiu, L., 2019. Dental microwear texture analysis of Homo sapiens sapiens: Foragers, farmers, and pastoralists. American journal of physical anthropology 169, 207- 226 
Schneider, C.A., Rasband, W.S., Eliceiri, K.W., 2012. NIH Image to ImageJ: 25 years of image analysis. Nature methods 9, 671.

Schour, I., Massler, M., 1941. The development of the human dentition. Journal of the American Dental Association 28, 11531160.

Scott, R.M., Halcrow, S.E., 2017. Investigating weaning using dental microwear analysis: A review. Journal of Archaeological Science: Reports 11, 1-11.

Sellen, D.W., Smay, D.B., 2001. Relationship between subsistence and age at weaning in "preindustrial" societies. Human Nature 12, 47-87.

Smith, B.H., 1984. Patterns of molar wear in hunter-gatherers and agriculturalists American Journal of Physical Anthropology 63, 39-56.

Sołtysiak, A., 2011. Cereal grinding technology in ancient Mesopotamia: evidence from dental microwear. Journal of $\mathrm{Ar}$ chaeological Science 38, 2805-2810. https://doi.org/https:// doi.org/10.1016/j.jas.2011.06.025

Teaford, M.F., Lytle, J.D., 1996. Brief communication: Diet-induced changes in rates of human tooth microwear: A case study involving stone-ground maize. American Journal of Physical Anthropology: The Official Publication of the American Association of Physical Anthropologists 100, 143-147.

Teira Brión, A., Amado, E., 2014. Molinos fuera de lugar. Fronteras y contextos de la molienda en la arqueología de la Edad del Hierro del noroeste ibérico. Revista d'Arqueologia Ponent 24, 271-287.
Tillier, A.M., Kaffe, I., Arensburg, B., Chech, M., 1998. Hypodontia of permanent teeth among Middle Palaeolithic hominids: An early case dated to ca.92.000 +- years BP at the Qafzeh site. International Journal of Osteoarchaeology 8, 1-6.

Trinkaus, E., 2018. An abundance of developmental anomalies and abnormalities in Pleistocene people. Proceedings of the National Academy of Sciences 115, 11941-11946.

Vaquero, M.R., Fernández, S.A., Fernández, C.A., Iglesias, A.A., Blain, H.A., Valcarce, R.F., Ruiz, M.L., 2009. Nuevas fechas radiométricas para la Prehistoria del noroeste de la Península Ibérica: la cueva de Valdavara (Becerreá, Lugo). Trabajos de prehistoria 66(1), 99-113.

Ventresca Miller, A., Hanks, B.K., Judd, M., Epimakhov, A., Razhev, D., 2017. Weaning practices among pastoralists: New evidence of infant feeding patterns from Bronze Age Eurasia. American Journal of Physical Anthropology 162, 409-422. https://doi.org/10.1002/ajpa.23126.

Zegan, G., Golovcencu, L., Romanec, C., Lesner, G., 2012. Hypodontia patterns and natural dental compensation movements. An orthopantomographic study. Romanian Journal of Oral Rehabilitation, 4(2), 90-97. 